\title{
SERUM ALANINE AMINOTRANSFERASE LEVELS, HEMATOCRIT RATE AND BODY WEIGHT CORRELATIONS BEFORE AND AFTER HEMODIALYSIS SESSION
}

\author{
Edmundo Pessoa Lopes, ' Luis Henrique B. C. Sette, II Jorge Bezerra C. Sette,

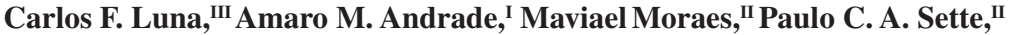

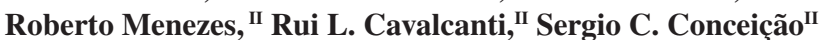

doi: $10.1590 / \mathrm{S} 1807-59322009001000002$

Lopes EP, Sette LHBC, Sette JBC, Luna CF, Andrade AM, Moraes M, Sette PCA, Menezes R, Cavalcanti RL, Conceição SC. Serum alanine aminotransferase levels, hematocrit rate and body weight correlations before and after hemodialysis session. Clinics. 2009;64(10):941-5.

PURPOSE: To evaluate alanine aminotransferase levels before and after a hemodialysis session and to correlate these values with the hematocrit rate and weight loss during hemodialysis.

PATIENTS AND METHODS: The serum alanine aminotransferase levels, hematocrit rate and body weight were measured and correlated before and after a single hemodialysis session for 146 patients with chronic renal failure. An receiver operating characteristic (ROC) curve for the serum alanine aminotransferase levels collected before and after hemodialysis was plotted to identify hepatitis $\mathrm{C}$ virus-infected patients.

RESULTS: The mean weight loss of the 146 patients during hemodialysis was $5.3 \%(\mathrm{p}<0.001)$. The mean alanine aminotransferase levels before and after hemodialysis were 18.8 and $23.9 \mathrm{IU} /$, respectively, denoting a significant $28.1 \%$ increase. An equally significant increase of $16.4 \%$ in the hematocrit rate also occurred after hemodialysis. The weight loss was inversely correlated with the rise in both the alanine aminotransferase level $(\mathrm{r}=0.3 ; \mathrm{p}<0.001)$ and hematocrit rate $(\mathrm{r}=0.5 ; \mathrm{p}<0.001)$. A direct correlation was found between the rise in alanine aminotransferase levels and the hematocrit during the hemodialysis session $(\mathrm{r}=0.4 ; \mathrm{p}<$ 0.001). Based on the ROC curve, the upper limit of the normal alanine aminotransferase level should be reduced by $40 \%$ relative to the upper limit of normal if the blood samples are collected before the hemodialysis session or by $60 \%$ if blood samples are collected after the session.

CONCLUSION: In the present study, significant elevations in the serum alanine aminotransferase levels and hematocrit rates occurred in parallel to a reduction in body weight after the hemodialysis session. These findings suggest that one of the factors for low alanine aminotransferase levels prior to hemodialysis could be hemodilution in patients with chronic renal failure.

KEYWORDS: Alanine aminotransferase; Hemodialysis; Hepatitis C; Chronic renal failure.

\section{INTRODUCTION}

The frequency of raised serum alanine aminotransferase (ALT) concentrations in patients who are infected with

${ }^{\text {I }}$ Department of Medicine, Universidade Federal de Pernambuco (UFPE) Recife/PE, Brazil.

II Dialysis Unit, NEFRO CLÍNICA - Recife/PE, Brazil.

III Centro de Pesquisa Aggeu Magalhães (FIOCRUZ) - Recife/PE, Brazil. Email: epalopes@uol.com.br

Tel.: 55813442.7596

Received for publication on May 09, 2009

Accepted for publication on July 01, 2009 the hepatitis $\mathrm{C}$ virus (HCV) and have chronic renal failure (CRF) that requires hemodialysis (HD) therapy has been reported to be between 4 and $67 \% .^{1-3}$ On the other hand, between 54 and $75 \%$ of patients with HCV antibodies (anti$\mathrm{HCV}$ ) without CRF have increased ALT levels. ${ }^{4}$ On the basis of these considerations, the ALT levels are assumed to be poor predictors of hepatocellular damage in the chronic HD population. ${ }^{1,2}$

A number of factors may explain the reduction in the ALT levels in HD patients, such as low or fluctuating serum viral load due to adsorption in the dialyzer membrane; non- 
virulent $\mathrm{HCV}$ strains; intermittent increases in the serum ALT concentration; or decreased levels of vitamin B6, a coenzyme of ALT. ${ }^{5-8}$ The ALT levels may also be lower before the HD session due to hemodilution and may increase after the session, depending on how much liquid is lost during dialysis.

Other studies have found that the ALT levels - even those not exceeding the upper limit of normal (ULN) - are higher in the anti-HCV positive patients in comparison to the anti$\mathrm{HCV}$ negative patients. Indeed, new criteria for the ULN of the ALT have been proposed for patients on HD. 5,7,9

A new ULN for the serum levels of ALT has also been proposed, corresponding to around $70 \%$ of the present ULN, for screening for liver damage not only in patients with CRF but also for the general population. One argument for this decrease is that sub-clinical conditions such as fatty liver disease and HCV infection had not yet been identified when the last ULN was established about 20 years ago. With the new ULN criteria, the ALT sensitivity should improve from 55 to $76 \%$ for the detection of patients with minimal to mild histological lesions, despite a reduction in specificity from 97 to $89 \% .{ }^{9}$ Recently, a population-based study carried out in Korea revealed that the risk of death from liver disease was higher among patients with ALT levels closer to the ULN in comparison to patients with lower ALT levels. Thus, a reduction to below $75 \%$ of the current normal cutoff values was suggested. ${ }^{11}$

Likewise, in trials using peginterferon and ribavirin for the treatment of patients with HCV infection and "normal" ALT concentrations, cases with a sustained virological response exhibited a greater decrease in ALT values than cases that did not respond. These results suggest that, in this group of patients, the "normal" ALT levels before therapy may be higher than in individuals without chronic hepatitis and that viremia clearance after treatment induces a subsequent reduction towards "true normal" ALT levels. ${ }^{12}$ Considering the clinical importance of these differences in ALT normality, a reduction of approximately $30 \%$ has been suggested for the conventional ULN serum ALT levels. ${ }^{13}$

The aim of the present study was to evaluate the ALT levels in patients with CRF and correlate those values with the hematocrit rate and weight loss before and after a single HD session. On the basis of these data, a more appropriate ALT cutoff value was established in order to better identify biochemical activity due to $\mathrm{HCV}$ infection in HD patients with CRF.

\section{PATIENTS AND METHODS}

In a dialysis unit in northeastern Brazil, 146 patients with CRF undergoing HD treatment were studied after giving informed consent. All patients over 16 years of age who fulfilled the following criteria were included: regular hemodialysis for at least 6 months and no history of alcohol intake (> $40 \mathrm{~g} /$ day). The study protocol was approved by the Research Ethics Committee of the University Federal de Pernambuco (Brazil).

The serum ALT was determined by an automated kinetic method (Abbott $\left.{ }^{\circledR}\right)$ in blood samples that were obtained immediately prior to and at the end of a single HD session. The serum concentration for each patient was divided by the ULN of the ALT according to gender (40 IU/L for women and $43 \mathrm{IU} / \mathrm{L}$ for men). The hematocrit rate was determined before and after the same HD session using a CELL-DYN 4000 analyzer. The antibody against hepatitis $\mathrm{C}$ virus (anti-HCV), hepatitis B virus surface antigen (HBsAg) and antibody against hepatitis B virus surface antigen (anti-HBs) levels were determined through enzyme immunoassays (Abbott ${ }^{\circledR}$ ).

For each analyzed variable, differences before and after the HD session were established as a gradient (after - before).

The statistical analysis was carried out using SPSS v8.0. The chi-squared test was used to determine the frequency difference, and Student's t-test was used to evaluate the mean differences. The degree of correlation between measurements before and after the HD session was assessed using the Pearson's correlation test. A significance level of $\mathrm{p}<0.05$ was chosen.

The best cutoff value for the ALT was established from a receiver operating characteristic (ROC) curve, which is the value that maximizes the sum of the sensitivity and specificity to identify the biochemical activity in HD patients with HCV antibodies.

\section{RESULTS}

Among the 146 patients, $88(60 \%)$ were men and 58 (40\%) were women; the average age was $48 \pm 15$ years (range 16-84 years). HCV antibodies were detected in $13(8.9 \%)$ patients; 11 patients $(7.5 \%)$ tested positive for HBsAg; and 95 patients (65\%) tested positive for anti-HBs.

The mean patient weight was $62.4 \pm 13.8 \mathrm{~kg}$ (range 37$119 \mathrm{~kg}$ ) before the HD session and $59.2 \pm 13.3 \mathrm{~kg}$ (range $36-113 \mathrm{~kg}$ ) after the session. The mean weight reduction was $3.3 \pm 1.3 \mathrm{~kg}(\mathrm{p}<0.001)$, denoting a $5.3 \%$ loss during each session (range $0-12.5 \%$ ).

The mean serum ALT levels before and after the HD session were $18.8 \pm 16.3 \mathrm{IU} / \mathrm{L}$ and $23.9 \pm 20.2 \mathrm{IU} / \mathrm{L}$, respectively, denoting an increase of $5.1 \mathrm{IU} / \mathrm{L}$ or $28.1 \%$ ( $<<$ 0.001). The mean hematocrit rates before and after the HD were $32.4 \% \pm 4.7$ and $37.7 \% \pm 6.1$, respectively, denoting a $5.3 \%$ increase in the hematocrit rate $(\mathrm{p}<0.001)$. This corresponded to an increase of $16.4 \%$ (Figure 1). 


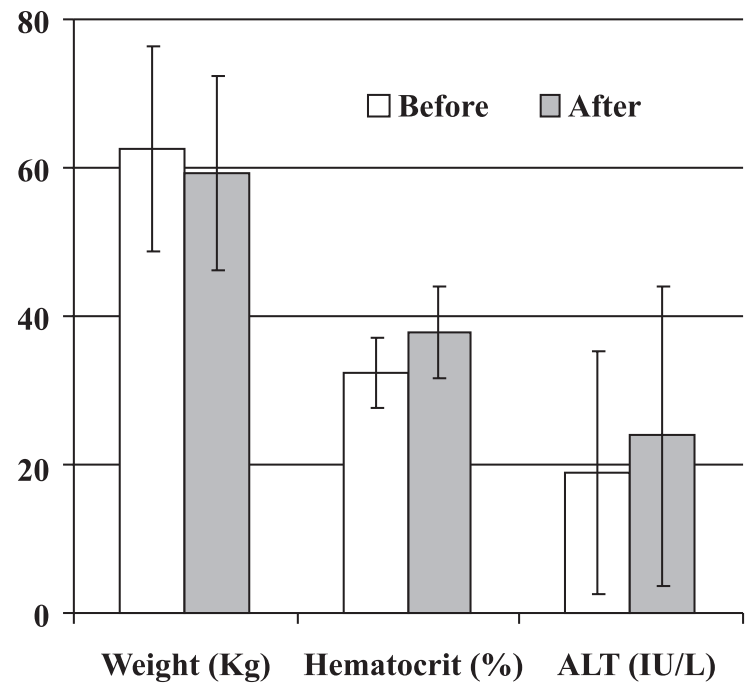

Figure 1 - Mean body weight $(\mathrm{p}<0.001)$, hematocrit rate $(\mathrm{p}<0.001)$ and serum levels of alanine aminotransferase (ALT; $p<0.001$ ) measured before and after a hemodialysis session in 146 patients with chronic renal failure, Recife, PE, Brazil

At the end of the HD session, 137 of the 146 patients (94\%) had raised ALT levels; on the other hand, 6 patients (4\%) maintained the same level, and 3 patients $(2 \%)$ had decreased levels. Regarding the hematocrit rates, 137 (94\%) patients had an increased hematocrit rate after the HD session; meanwhile, 4 patients $(2.7 \%)$ maintained their rate, and the rate dropped in 5 patients $(3.4 \%)$. Only one patient maintained the same body weight, in the other 145 patients $(99.3 \%)$ the weight dropped at the end of the HD session.

The weight loss that occurred throughout the HD session exhibited an inverse correlation with the increase in both the ALT serum levels $(r=0.3 ; p<0.001)$ and the hematocrit rate $(\mathrm{r}=0.5 ; \mathrm{p}<0.001)$. A direct correlation was found for the parallel increase in the ALT and hematocrit rate $(\mathrm{r}=0.4 ; \mathrm{p}<$ 0.001) throughout the HD session (Figure 2).

To determine the ROC curves for the mean ALT values before and after the HD session, the $11 \mathrm{HBsAg-positive}$ patients were excluded from the analysis (one of these was also anti-HCV positive). Among the 135 remaining patients, 80 (59\%) were men, and the average age was 48 years. Among the 123 anti-HCV-negative patients, $6(4.9 \%)$ exhibited high ALT levels before the HD session; among the 12 anti-HCV positive patients, only $1(8.3 \%)$ exhibited high ALT levels before the HD session $(\mathrm{p}=0.86)$. After the HD session, 9 (7.3\%) of the 123 anti-HCV negative patients had higher ALT levels, and 2 (16.6\%) of the 12 anti-HCVpositive patients had higher ALT levels $(\mathrm{p}=0.56)$.

Among the 12 anti-HCV-positive patients, the mean ALT divided by the ULN (ALT/ULN) before and after the HD session was $0.54 \pm 0.29$ and $0.67 \pm 0.34$, respectively $(\mathrm{p}=$ 0.32). Among the 123 anti-HCV-negative patients, the ALT/

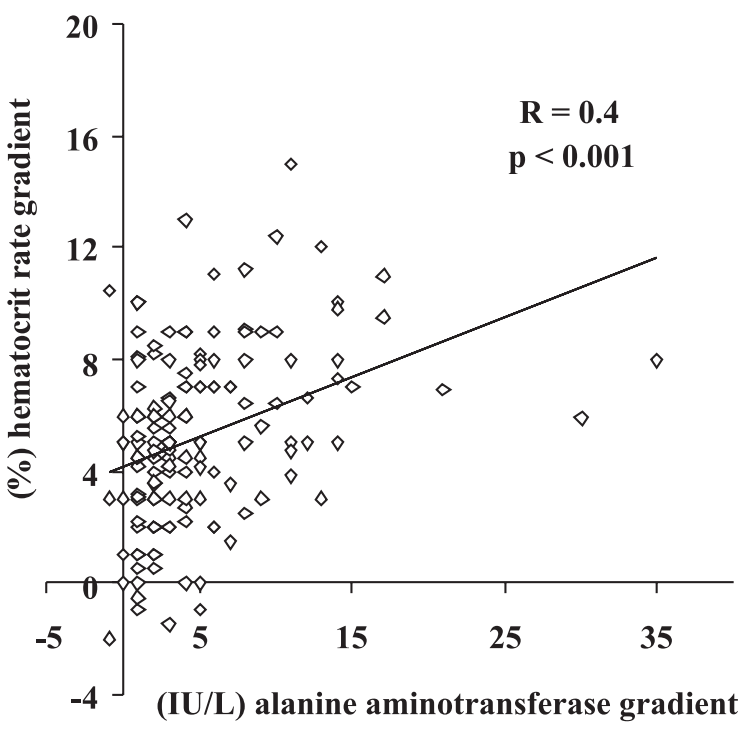

Figure 2 - Correlation between the serum alanine aminotransferase gradient and hematocrit rate gradient before and after a hemodialysis session in 146 patients with chronic renal failure, Recife, PE, Brazil

ULN before and after the HD session was $0.44 \pm 0.39$ and $0.56 \pm 0.48$, respectively $(\mathrm{p}=0.03)$.

The best serum ALT concentration cutoff value for identifying biochemical activity in the anti-HCV positive patients before the HD session was 0.40 , or $40 \%$ of the ULN. This value corresponded to $75 \%$ sensitivity, $59 \%$ specificity, and positive and negative predictive values of 15 and $96 \%$, respectively. After the HD session, the best serum ALT concentration cutoff value for identifying biochemical activity in the anti-HCV positive patients was 0.60 , or $60 \%$ of the ULN. This value corresponded to $66 \%$ sensitivity, $65 \%$ specificity, and positive and negative predictive values of 16 and $95 \%$, respectively.

In clinical practice, we recommend that the ULN for women decreases from $40 \mathrm{IU} / \mathrm{L}$ to $16 \mathrm{IU} / \mathrm{L}$ if the ALT was collected before the HD session or to 24 IU/L if the ALT was collected after the HD session. For men, the ULN of the ALT would then decrease from $43 \mathrm{IU} / \mathrm{L}$ to $17 \mathrm{IU} / \mathrm{L}$ if collected before the HD session or to $28 \mathrm{IU} / \mathrm{L}$ if collected after the HD session (Table 1).

Table 1 - Mean body weight $(\mathrm{kg})$, serum levels of alanine aminotransferase (IU/L), and hematocrit rate (\%) measured before and after a hemodialysis session in 146 patients with chronic renal failure at Recife, PE, Brazil

\begin{tabular}{lccc}
\hline & \multicolumn{2}{c}{ Hemodialysis session } & \multirow{2}{*}{$\mathbf{p}$} \\
\cline { 2 - 3 } & Before & After & \\
\hline Body weight (kg) & $62.4 \pm 13.8$ & $59.2 \pm 13.3$ & 0.001 \\
Alanine & $18.8 \pm 16.3$ & $23.9 \pm 20.2$ & 0.001 \\
aminotransferase (IU/L) & & & \\
Hematocrit rate (\%) & $32.4 \pm 4.7$ & $37.7 \pm 6.1$ & 0.001 \\
\hline
\end{tabular}




\section{DISCUSSION}

The serum ALT concentration is lower in patients with CRF submitted for HD treatment and is a poor predictor of $\mathrm{HCV}$ infection in this population. Evaluating the laboratory and histological data from 92 patients with HCV-related liver disease (46 renal transplant candidates and 46 control subjects with normal renal function), Cotler et al. ${ }^{13}$ found that the serum ALT levels were significantly lower in patients with CRF. The exact reason for the lower ALT in patients with CRF needs to be fully elucidated. One possibility is due to liver cells protection by hepatocyte growth factor (HGF), which is higher concentration in patients with CRF for whom HD is recommended. ${ }^{14}$ The lower ALT activity in HD patients may also be a consequence of a smaller serum HCV viral load, due to the adsorption of the virus genome in the dialyzer membrane or to the induction of endogenous interferon caused by the HD. ${ }^{15}$ On the other hand, a recent article reported that $\mathrm{HCV}$-infected patients with $\mathrm{CRF}$ submitted for HD have lower ALT levels, but the viral load and the genotype distribution are similar to those found in $\mathrm{HCV}$-infected patients with normal renal function. ${ }^{16}$

Another hypothesis to explain the lower serum levels of ALT in patients with CRF could be the severity of the impairment of renal function induced by glomerular damage. In fact, Fabrizi et al. ${ }^{7}$ found significantly lower serum ALT activity in patients on chronic HD than in predialysis patients with CRF, and they reported a correlation between the reduced ALT activity and the degree of renal function in these patients. In a large cohort of pre-dialysis patients, ${ }^{17}$ the $\mathrm{HCV}$-infected patients had significantly higher ALT levels compared to the non-infected patients, and the accuracy of the ALT in detecting the HCV infection was 92\%. Thus, Lemos et al. ${ }^{17}$ have suggested that the serum ALT level in pre-dialysis patients may be a good marker of $\mathrm{HCV}$ infection.

Hung et al. ${ }^{18}$ evaluated 90 patients on continuous ambulatory peritoneal dialysis (CAPD) and 526 healthy adults and found a mean ALT concentration of $15 \mathrm{IU} / \mathrm{L}$ in the CAPD patients as opposed to $22 \mathrm{IU} / \mathrm{L}$ in the control group $(\mathrm{p}<0.0001)$. Such data support the fact that patients with CRF have lower levels of ALT, regardless of HD.

In the present study, the ALT levels also increased significantly after the HD session in both patient groups (with and without anti-HCV). This increase may be a consequence of the loss of liquid during the session, thereby correcting the prior hemodilution. This premise is reinforced by the direct correlation found between the ALT gradient and the hematocrit rate throughout HD and the inverse correlation between the ALT gradient and the weight loss during the HD session. Furthermore, Conway et al. ${ }^{19}$ evaluated the serum cardiac troponin levels in patients undergoing chronic HD and found that the concentration of this enzyme was significantly higher after the HD session as compared to before the session. The authors suggested that this rise in troponin levels following HD was probably due to hemoconcentration, as was also detected with the hematocrit rate in the same study.

The possibility that the rise in the ALT levels is due to hemodilution correction following the HD sessions does not explain the reduced ALT levels in the CAPD patients, who theoretically would not have hemodilution. Another possibility to explain the lower serum levels of ALT in patients with CRF could be hypotension-induced liver cell injury during the HD session. However, ischemic hepatitis is generally related to hepatocyte necrosis and these patients exhibits a higher serum ALT concentration than that found in our patients. Perhaps hemodilution also contributes to the reduction in the ALT levels before the session in patients with CRF requiring regular HD therapy. In the present study, we detected an approximately $25 \%$ increase in the serum ALT levels after the HD session, but this increase was not sufficient to exceed the conventional ULN value. In fact, after HD, only 2 of the 12 patients (16.6\%) with chronic HCV infection had ALT concentrations above the conventional ULN, thereby supporting the need for a lower ALT cutoff value.

In conclusion, the present study has revealed that most of the CRF patients submitted to chronic HD treatment had serum ALT concentrations below the ULN, even though these levels were higher than in patients on HD without HCV infection. The ALT levels, however, underwent a significant increase after the HD session, probably due to the correction in hemodilution, as was also observed with the hematocrit rate. Therefore, by reducing the ALT cutoff value to about $60 \%$ of the previously established value and collecting the blood sample after the HD session, it is possible to better identify patients with hepatocellular damage. Further studies, however, are needed in order to validate the reduced ULN for the serum ALT concentration in clinical practice. 


\section{REFERENCES}

1. Al-Wakeel J, Mailk GH, Al-Mohaya S, Mitwalli A, Baroudi F, El Gamal $\mathrm{H}$, et al. Liver disease in dialysis patients with antibodies to hepatitis $\mathrm{C}$ virus. Nephrol Dial Transplant 1996;11:2265-8.

2. Yuki N, Ishida H, Inoue T, Tabat T, Matsushita Y, Sasaki Y, et al. Reappraisal of biochemical hepatitis $\mathrm{C}$ activity in hemodialysis patients. J Clin Gastroenterol. 2000;30:187-94.

3. Fabrizi F, Lunghi G, Ganeshan SV, Martin P, Messa P. Hepatitis C virus infection and the dialysis patient. Semin Dial. 2007;20:416-22.

4. Alberti A, Noventa F, Benvegnù L, Boccato S, Gatta A. Prevalence of liver disease in a population of asymptomatic persons with hepatitis $\mathrm{C}$ virus infection. Ann Inter Med. 2002;137:961-4.

5. Guh JY, Lai YH, Yang CY, Chen SC, Chuang WL, Hsu TC, Chen HC, Chang WY, Tsai JH. Impact of decreased serum transaminase levels on the evaluation of viral hepatitis in hemodialysis patients. Nephron. 1995;69:459-65.

6. Yasuda K, Okuda K, Endo N, Ishiwatari Y, Ikeda R, Hayashi H, Kobayashi S, Irie Y. Hypoaminotransferasemia in patients undergoing long-term hemodialysis: clinical and biochemical appraisal. Gastroenterology. 1995;109:1295-300.

7. Fabrizi F, Lunghi G, Finazzi S, Colucci P, Pagano A, Ponticelli C, et al. Decreased serum aminotransferase activity in patients with chronic renal failure: impact on the detection of viral hepatitis. Am J Kidney Dis. 2001;38:1009-15.

8. Ono K, Ono T, Matsumata T. The pathogenesis of decreased aspartate amino-transferase and alanine aminotransferase activity in the plasma of hemodialysis patients: the role of vitamin B6 deficiency. Clin Nephrol. 1995;43:405-8.

9. Lopes EPA, Gouveia EC, Albuquerque ACC, Sette LHBC, Mello LA, Moreira RC, et al.. Determination of the cutoff value of serum alanine aminotransferase in patients undergoing hemodialysis to identify biochemical activity in patients with hepatitis $\mathrm{C}$ viremia. J Clin Virol. 2006;35:298-302.
10. Prati D, Taioli E, Zanalla A, Torre ED, Butell S, Vecchio ED, et al. Updated definitions of healthy ranges for serum alanine aminotransferase levels. Ann Inter Med. 2002;137:1-9.

11. Kim HC, Nam CM, Jee SH, Han KH, Oh DK, Suh I. Normal serum aminotransferase concentration and risk of mortality from liver diseases: prospective cohort study. Br Med J. 2004;328:983-6.

12. Prati D, Shiffman ML, Diago M, Gane E, Reddy KR, Pockros P, et al. Viral and metabolic factors influencing alanine aminotransferase activity in patients with chronic hepatitis C. J Hepatol. 2006;44:679-85.

13. Cotler SJ, Diaz G, Gundlapalli S, Jakate S, Chawla A, Mital D, et al. Characteristics of hepatitis $\mathrm{C}$ in renal transplant candidates. J Clin Gastroenterol. 2002;35:191-5.

14. Rampino T, Arbustini E, Gregorini M, Guallini P, Libetta C, Maggio M, et al. Hemodialysis prevents liver disease caused by hepatitis $\mathrm{C}$ virus: role of hepatocyte growth factor. Kidney Int. 1999;56:2286-91.

15. Badalamenti S, Catania A, Lunghi G, Covini G, Bredi E, Brancaccio D, et al. Changes in viremia and circulating interferon- during hemodialysis in hepatitis $\mathrm{C}$ virus-positive patients: only coincidental phenomena? Am J Kidney Dis. 2003;42: 143-50.

16. Azevedo HA, Villela-Nogueira CA, Perez RM, Segadas-Soares JA, Takahashi C, Gaburo, et al. Similar HCV viral load levels and genotype distribution among end-stage renal disease patients on hemodialysis and $\mathrm{HCV}$-infected patients with normal renal function. J Nephrol. 2007;20:609-16.

17. Lemos LB, Perez RM, Lemos MM, Draibe SA, Silva IS, Silva AEB, et al. Hepatitis $\mathrm{C}$ among predialysis patients: Prevalence and characteristics in a large cohort of patients. Nephron Clin Pract. 2008;108:c135-40.

18. Hung KY, Lee KC, Yen KD, Tsai TJ, Chen WY. Revised cut off values of serum aminotransferase in detecting viral hepatitis among CAPD patients: experience from Taiwan, an endemic area for hepatitis B. Nephrol Dial Transplant. 1997;12:180-3.

19. Conway B, McLaughlin M, Sharpe P, Harty J. Use of cardiac troponin T in diagnosis and prognosis of cardiac events on chronic haemodialysis. Nephrol Dial Transplant. 2005;20:2759-64. 
